\title{
Influences of the Cloud Shape of Fuel-Air Mixtures on the Overpressure Field
}

\author{
Chunhua Bai, Ye Wang, Jianping Li, and Mingsheng Chen \\ State Key Laboratory of Explosion Science and Technology, Beijing Institute of Technology, Beijing 100081, China \\ Correspondence should be addressed to Ye Wang; wangye_0422@126.com
}

Received 16 December 2015; Revised 11 April 2016; Accepted 11 April 2016

Academic Editor: Isabelle Sochet

Copyright (C) 2016 Chunhua Bai et al. This is an open access article distributed under the Creative Commons Attribution License, which permits unrestricted use, distribution, and reproduction in any medium, provided the original work is properly cited.

\begin{abstract}
This paper presents an experiment system in the open field, which comprises a charge structure (approximately $166.2 \mathrm{~kg}$ ), a highspeed camera subsystem, and a pressure measurement subsystem. Through a series of experiments under the cylindrical clouds with different diameters, heights, and diameter-to-height ratios $(D: H)$, the influences of various cloud shapes on the overpressure field were analyzed and discussed. Based on the experimental results, the overpressure field was divided into two zones: detonation wave zone and shock wave zone. It is found that the overpressure of shock waves at the same distance from the explosion center increased with the diameters, but the variations of heights had little impact on the overpressure. Therefore, the pancake-shaped cloud of fuelair mixtures is the optimal shape for obtaining the wider overpressure field. Moreover, it is found that the overpressure field gets the maximum under the diameter-to-height ratios of 5.7 in the same distance within the studied range.
\end{abstract}

\section{Introduction}

Some fuels, such as hydrocarbons and hydrocarbon oxides, cannot blast when they are stored separately. However, when they are mixed with the ambient air under the dynamic load, they form a certain shape vapor cloud of fuel-air mixtures (fuel-air cloud) and obtain explosive properties. The fuelair clouds detonate if a powerful igniter source provides the proper energy for the initiation and the concentration of fuel in the cloud reaches the explosive limits. The detonation of fuel-air cloud produces the high overpressure, temperature, and impulse. Such conditional detonation of fuel-air cloud results in a serious explosion accident when the leaked fuel in storage, process, sale, and transport satisfies the formation condition of fuel-air cloud. However, it is an important step in the reformation for routine weapons [1] to make use of the phenomenon in the military field and the fuel-air cloud is also known as Fuel-Air Explosives (FAE).

Shock waves are the major hazard in explosion accidents. The overpressure is one of the main parameters to evaluate the risky level of shock waves. The characteristics of the overpressure of fuel-air mixtures have been extensively studied in recent years to recognize the cloud detonation process through accurate modeling and estimation conditions. Therefore, it is important to study the parameters affecting the detonation of the fuel-air cloud resulting in the overpressure field. Up to now, influencing factors of the overpressure of fuel-air cloud have been widely studied. Some works on the enclosed space have paid attention to the influencing factors of the overpressure production process of gas-liquid twophase, gas-solid two-phase, and gas-liquid-solid three-phase within the vessel in laboratory [2-7], such as the location of the detonation initiation point $[8,9]$, energy [10] and ignition way [11], particle size [12] of fuel-air mixtures, and fuel type [13]. Moreover, the related computational model had been established $[8,14]$.

The cloud shapes effectively affect the damage scope of the explosion near the ground [15]. Consequently, in the study, we carried out an experiment in the open field, measured cloud shape data with a high-speed color photography system, and recorded the overpressure values with a pressure measurement system. Based on a series of experiments carried out 


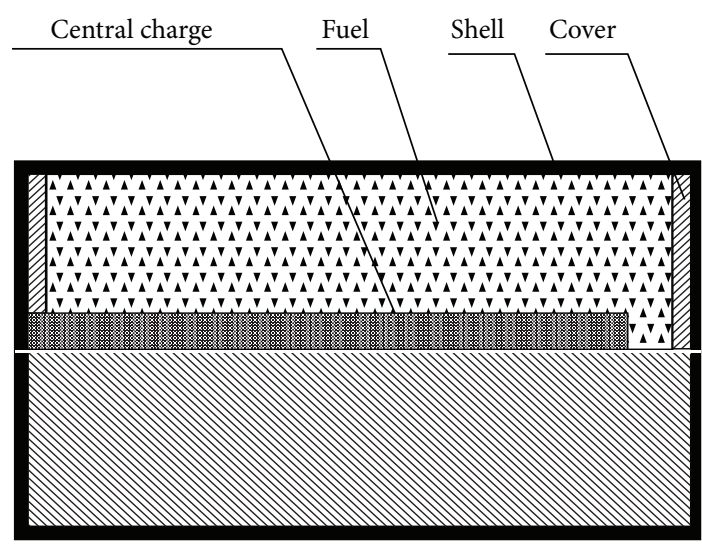

FIGURE 1: Sketch of charge structure (not to scale).

in this system, we studied and discussed the overpressure of fuel-air mixtures under different diameters and heights of cloud.

\section{Experimental Apparatus and Procedures}

2.1. General. The experimental system consisted of a charge structure (approximately $166.2 \mathrm{~kg}$ ) coupled with a high-speed camera subsystem and a pressure measurement subsystem. The experiments were carried out in the open field with the charge structure. The detonator was placed at the center of the bottom cover with the radius of $1.5 \mathrm{~m}$.

The process of change in the shape of cloud was monitored by means of the high-speed camera subsystem and the overpressure data were captured by the pressure measurement subsystem.

2.2. Materials. Solid-liquid mixtures were chosen as the fuels in the study due to their wide range of explosive limits in air, high damage potential, and high sensitivity to detonation [16]. The solid component was aluminum powder and the liquid component was ether. The physical and chemical properties of aluminum-ether mixtures are given in Table 1. TNT was selected as high explosive in the central charge because of the low-detonation velocity and low pressure blasting compared to RDX and HMX. Moreover, TNT was chosen as the initiator charge for cloud detonation test [17].

2.3. Preparations of Explosive Charges. TNT was shaped into the cylindrical shape by press-fitting method to achieve the density of $1.63 \mathrm{~kg} / \mathrm{m}^{3}$ and the total mass of TNT in the central charge is $1.08 \mathrm{~kg}$. TNT $(8 \mathrm{~kg})$ in the initiator with the size of $\phi$ $150 \mathrm{~mm} \times 100 \mathrm{~mm}$ was prepared for detonation.

2.4. Charge Structure. As shown in Figure 1, the charge structure is composed of shell, fuel, center charge, fuse, and detonator. The charge structure was designed as a cylinder to form the cylindrical cloud. The inner diameter and the length of the charge structure were, respectively, $0.182 \mathrm{~m}$ and $1.1 \mathrm{~m}$. The total fuel mass in each charge structure was $125 \mathrm{~kg}$. The shell of vessel was made of aluminum alloy materials and $0.3 \mathrm{~mm}$ thick 16 equispaced indentations on its surface allowed the fast formation of homogeneous clouds. Both the bottom and top covers were welded to the shell. In the experimental charge structure, the central charge was ignited by a fuse in the central part of the center tube.

2.5. Fuel Dispersion Trials. The experimental setup shown in Figure 2 was adopted in the fuel dispersion tests without using initiator. The fuel dispersion process was recorded with a V12 high-speed color photography system. The photographing frequency was 1000 frames per second. The recording period was no less than $2 \mathrm{~s}$ and the resolution ratio of each photo was $1280 \times 720$.

2.6. Overpressure Trial of Fuel-Air Mixtures. According to different delay time, the fuel-air mixture was used to form the certain cloud shape and the cloud was detonated by a separate initiator charge. The test parameters are as given below: canister stand-off $(1.5 \mathrm{~m})$, initiator stand-off $(2.8 \mathrm{~m})$, the interval between canister and booster $(1.5 \mathrm{~m})$, and delay of initiator charge [TNT] (240 280 ms).

The detonations were monitored by means of the pressure measurement subsystem composed of the pressure testing device and synchronization control device. The pressure testing device was composed of Kistler pressure sensors, sensor adapters, and data collection unit for storing the voltage values. Synchronization control device sent the order to the data collection systems to record the electricity signal as soon as it detected the detonation signal and the recorded data were stored in the hard disk. The pressure sensors were mounted on the steel plate with the diameter of $0.3 \mathrm{~m}$ and the plate surface was parallel to the ground. The main mounting lines were arranged from the charge center in four directions and the distances between the charge center and the sensors were, respectively, $5 \mathrm{~m}, 8 \mathrm{~m}, 10 \mathrm{~m}, 15 \mathrm{~m}, 20 \mathrm{~m}, 30 \mathrm{~m}, 40 \mathrm{~m}$, and $50 \mathrm{~m}$ (Figure 2).

For the detonation with a given cloud shape, the measured pressure varies with time and reaches the peak values in the front of pressure wave. The peak values are defined as the peak overpressure. With the measurement subsystem, the overpressure can be obtained on the basis of the given sensor's sensitivity and magnification through calculation. The relationship of voltage and overpressure is expressed as

$$
p=\frac{V_{m} S_{q 1}}{K S_{q}},
$$

where $p$ is the overpressure; $V_{m}$ is the recorded voltage; $K$ is the charge amplifier magnification; $S_{q 1}$ is charge amplifier sensitivity; $S_{q}$ is sensor's sensitivity.

2.7. Experimental Process. In order to measure the overpressure accurately, it is important to check and arrange all the devices before the experiments (Figure 2). Firstly, the experimental charge structures were mounted on a rack which was $1.4 \mathrm{~m}$ above the ground, with the structural center of the bottom cover which was $1.5 \mathrm{~m}$ above the ground. Secondly, two $4 \mathrm{~m}$ high coupled signposts perpendicular to 


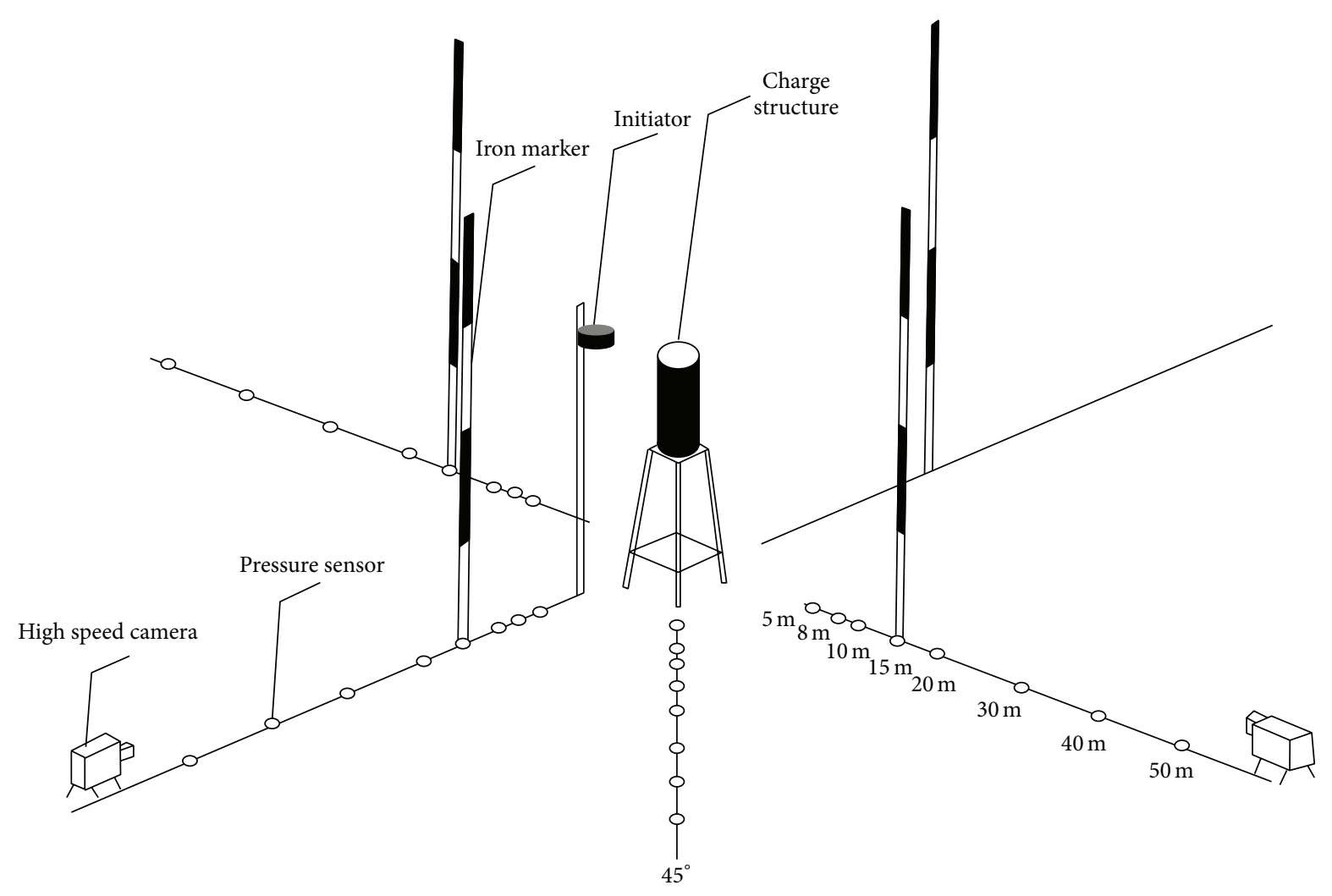

FIgURE 2: Experimental layout.

each other were arranged in the center of the bottom cover. Finally, the trigger times of pressure sensors were tested to be no less than 20. Moreover, two high-speed digital cameras were mounted at the same height and with the safety explosion distance from the bottom port center.

After checking the devices, the fuse was triggered via an external signal firstly and the center charge then produced a powerful blast. The blast caused the shell damage, thus dispersing the fuel to form the certain fuel-air cloud in the air. After the delay of $240 \sim 280 \mathrm{~ms}$, the fuel-air cloud was initiated by the detonator. Meanwhile, the pressure measurement subsystem collected the data and the experimental photos were taken by the high-speed cameras.

\section{Results and Discussion}

3.1. Formation of Fuel-Air Cloud. The data of cloud dispersal process were acquired by a V12 high-speed color photography system. The photographing frequency was 1000 frames per second. Recording time was no less than $2 \mathrm{~s}$ and the resolution ratio of each photo was $1280 \times 720$.

The fuel was dispersed by central charge. After a certain period, fuel-air mixture formed cylindrical fuel-air clouds. According to the characteristics of cylindrical clouds, the diameter $(D)$ and height $(H)$ represented the cloud dispersal process. Thus the ratio of diameter to height (diameter-toheight ratio, $\varepsilon$ ) is defined as

$$
\varepsilon=\frac{D}{H} .
$$

Figure 3 shows the typical photos of fuel-air cloud dispersal process. In order to obtain the actual size of cloud, the pixel of the photos was converted into the length unit of meter according to the signposts. The typical transferred $\varepsilon$ varying with time is shown in Figure 4. It is indicated that $\varepsilon$ increases with time and then reaches the maximum value. The values decreased firstly and then vibrated around a certain value. After a short time, $\varepsilon$ decreased. The cloud dispersal process can be divided into three successive stages: the acceleration phase, the deceleration phase, and the turbulence phase. As shown in Figure 4, the horizontal motion of cloud is quicker than the vertical motion in the acceleration phase and the horizontal motion speed decreases more severely than the vertical motion in the deceleration phase. However, the horizontal motion was more and more obvious and the cloud expanded stably in the turbulence phase. On the basis of the dispersal process, the cylinder cloud of fuel-air mixtures could be formed in the turbulence phase.

3.2. Overpressure at Different Cloud Diameters. The experiments of fuel-air mixture explosions were carried out under the same ignition conditions: relative humidity of $90 \%$, initial temperature of fuel-air mixture at $26^{\circ} \mathrm{C}$, and the wind speed less than $5 \mathrm{~m} \cdot \mathrm{s}^{-1}$.

The cylinder shapes of the cloud with different diameters at the same cloud height of $4 \mathrm{~m}$ were chosen and compared with each other. The peak overpressure of each experiment was calculated as the average of the measured values at four points with the identical distance from the explosion center. 


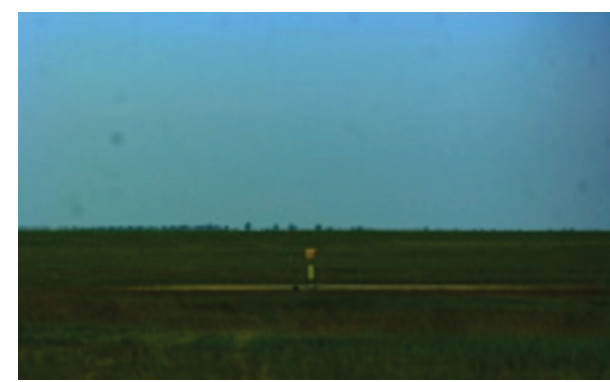

Origin

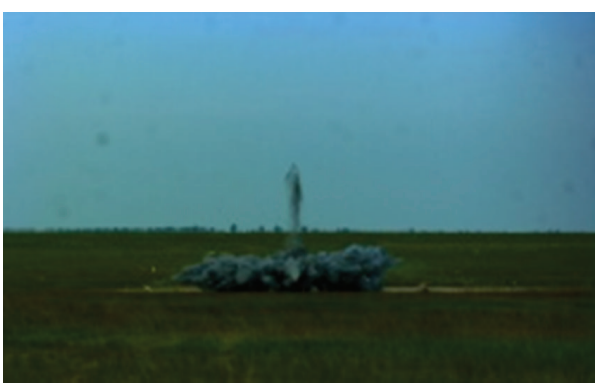

Deceleration phase

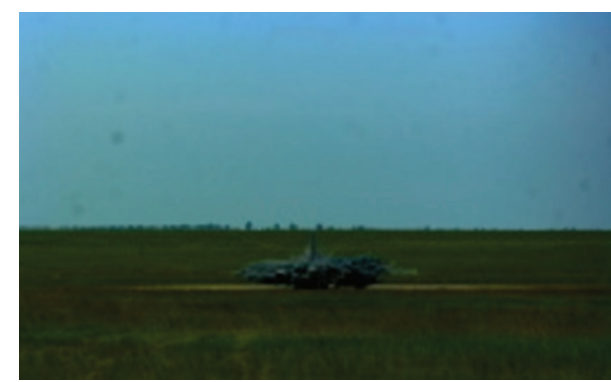

Acceleration phase

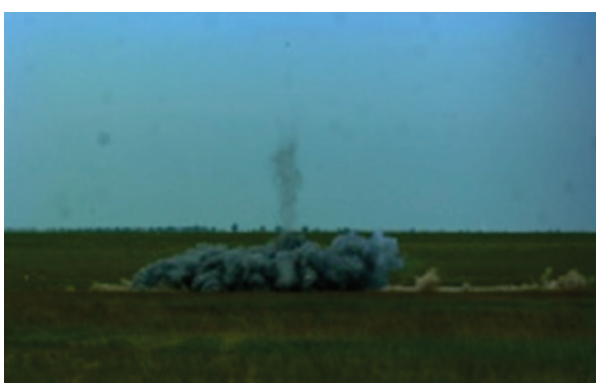

Turbulence phase

FIGURE 3: Photos of cylinder clouds taken by a high-speed camera.

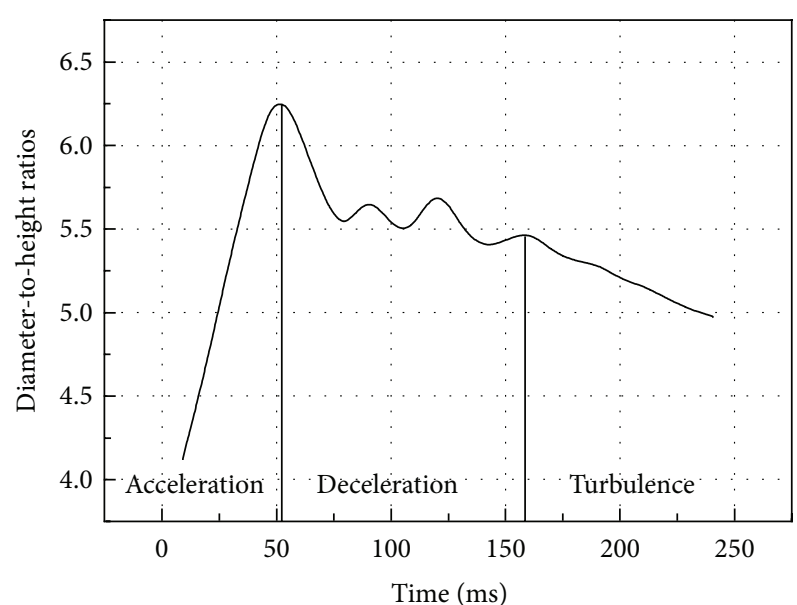

FIGURE 4: Diameter-to-height ratios $\varepsilon$ of cylinder cloud of fuel-air mixtures versus time.

TABLE 1: Changing rate of various diameters at the fixed distances.

\begin{tabular}{lcc}
\hline \multirow{2}{*}{ Distance $/ \mathrm{m}$} & \multicolumn{3}{c}{ Increase rate\% } \\
& $\Delta D=D_{2}-D_{1}=0.3$ & $\Delta D=D_{3}-D_{2}=0.9$ \\
\hline $5-10$ & - & - \\
15 & 54.76 & 13.33 \\
20 & 54.84 & 21.88 \\
30 & 48.39 & 21.74 \\
40 & 29.17 & 16.13 \\
50 & 10.53 & 14.29 \\
\hline
\end{tabular}

In the typical results of experiments in Table 1 , the values of three columns, respectively, correspond to the cases of different diameters $22.7 \mathrm{~m}, 23.0 \mathrm{~m}$, and $23.9 \mathrm{~m}$.

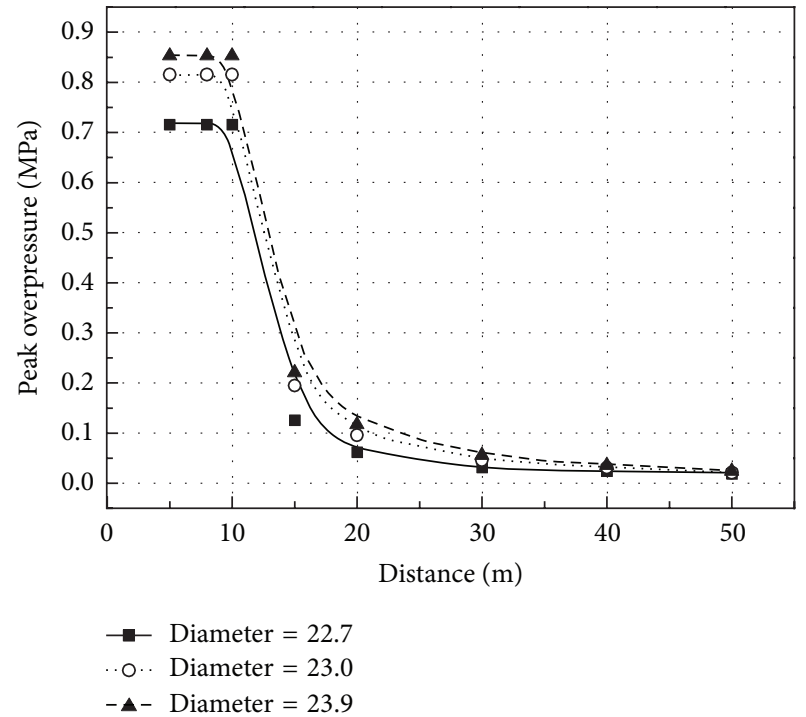

FIgURE 5: Comparison of overpressure under various diameters versus different distances.

Figure 5 indicates that the maximum peak overpressure of fuel-air cloud in each experiment is acquired within the range of $0 \mathrm{~m}$ and $10 \mathrm{~m}$ and the peak overpressure decreases with the increase in the distance.

The explosive cloud ignited by the powerful source immediately generated the detonation waves. When the detonation waves traveled to the ground along the propagation direction, it caused a Mach reflection which accelerated chemical reactions and raised the temperature. As a result, the detonable cloud produced the higher explosive overpressure and obtained the maximum overpressure. Then the detonation 
waves stably propagated. When it spread to the cloud border, detonation waves were attenuated to shock waves. According to the distribution law of peak overpressures, the overpressure field is divided into two zones: detonation wave zone and shock wave zone. In the experiment, in the detonation wave zone, the peak overpressure of fuel-air cloud was slightly changed slightly within the testing height range from $0 \mathrm{~m}$ to $10 \mathrm{~m}$. In shock wave zone, the peak overpressures decrease significantly in the testing height range from $10 \mathrm{~m}$ to $50 \mathrm{~m}$.

For the purpose of comparison, peak overpressures obtained within the same distance in different diameters are also shown in Figure 5. The overpressures within every fixed distance under the diameter of $23.9 \mathrm{~m}$ were the largest among the three cases of three different diameters and the largest overpressure was $0.853 \mathrm{MPa}$.

Table 1 summarizes the decrements of shock waves in different diameters. The decrements of shock waves almost were decreased with the increase in the diameter. The larger diameter increased the maximum overpressure at the same distance in the detonation waves and the increasing rate was between $10.53 \%$ and $54.84 \%$. In the shock waves, the decrements of peak overpressures showed the similar changing trend with that of the detonation waves. This means that the peak overpressure increases with the increase in the diameter at the same distance. Therefore, the larger diameter can significantly enhance the explosion influencing range under the same fuel mass.

The higher overpressure was produced in the larger diameter at the same distance and the decrease rate was smaller than that in the near field of shock waves. However, the decrease rates were consistent with each other in the far field of shock waves. For example, the overpressures within the diameter range from $22.7 \mathrm{~m}$ to $23.9 \mathrm{~m}$ were close to that at the distance of $50 \mathrm{~m}, 0.02 \mathrm{MPa}$. As a result, the overpressures in the far field of shock wave showed no obvious difference among different diameters.

3.3. Overpressure at Various Cloud Heights. The experimental results on the overpressure at different heights $(3.8 \mathrm{~m}, 3.9 \mathrm{~m}$, and $4.1 \mathrm{~m}$ ) were obtained, respectively. The overpressures determined at the same distance are shown in Figure 6.

As shown in Figure 6, the changing trend of overpressure of cylindrical cloud in each experiment is the same under the three diameters. Thus, the measurement field is divided into the detonation wave zone and shock wave zone.

Comparison of the peak overpressure under various heights with the same diameter of fuel-air cloud showed that the peak overpressure in the shock waves varied with the height. Although the peak overpressure varied with the height, the gaps among different groups decreased with the propagation of shock waves. In the shock wave zone, the peak overpressures gradually became close to each other. Therefore, compared with the diameter, the height within the studied range had little impact on the peak overpressure in the shock wave zone. According to the experimental result, the peak overpressure reached the highest value under the height of $3.9 \mathrm{~m}$.

In order to expand the explosion scope, during the selection of the cloud shape, the following two points can

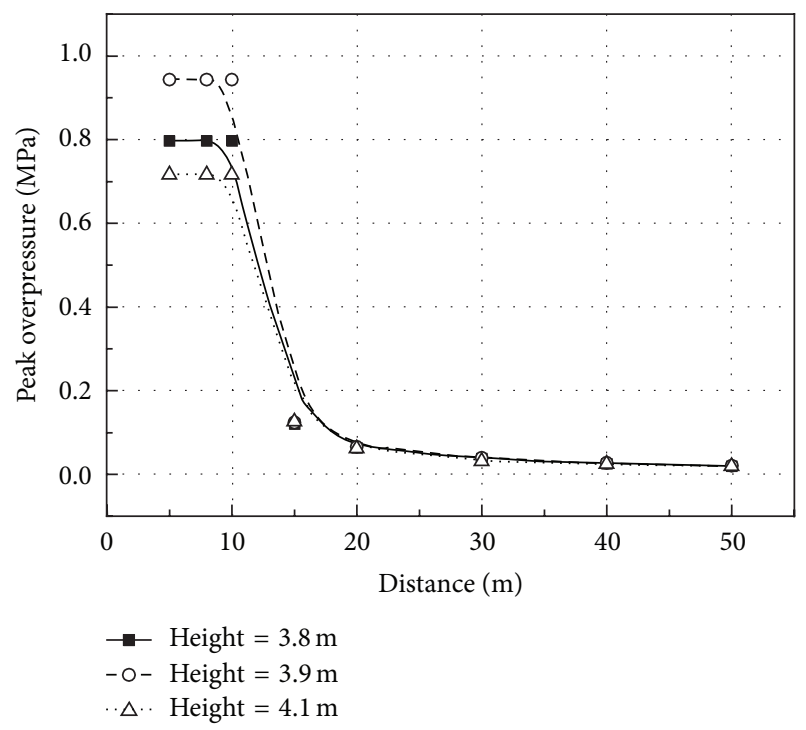

FIGURE 6: Comparison of overpressure under various heights versus different distances.

be referenced. Firstly, under the pancake-shaped cloud, the range of overpressure field can be increased. Secondly, the larger diameter can realize the purpose within the certain height range.

3.4. Overpressure at Various Diameter-to-Height Ratios of Cloud. According to the experiment results of cylindrical cloud with different diameters and heights, the pancakeshaped cloud with the larger diameter can boost the impact range of overpressure. Thus, the main characteristics of the overpressure field are largely dependent on the $\varepsilon$ of the pancake-shaped cloud.

The pancake-shaped clouds with the same volume and fuel mass were ignited at various $\varepsilon$ under the same experimental conditions. Table 2 shows the results of overpressure within the same distance at various $\varepsilon$ of 5.6, 5.7, and 5.8, respectively. Similarly, the overpressures in each experiment were divided into detonation wave zone and shock wave zone. When the $\varepsilon$ of pancake-shaped cloud was between 5.6 and 5.7, the maximum overpressure under the same distance increased with the increase in $\varepsilon$; when the $\varepsilon$ was between 5.7 and 5.8 , the increasing rate of overpressure decreased with the increase in $\varepsilon$. When the $\varepsilon$ of pancake-shaped cloud was 5.7, the overpressure at the various distances reached its maximum value $(0.943 \mathrm{MPa})$ in the detonation wave field and $0.132 \mathrm{MPa}$, $0.075 \mathrm{MPa}, 0.047 \mathrm{MPa}$, and $0.032 \mathrm{MPa}$ in the shock wave field.

According to the above result, the $\varepsilon$ of pancake-shaped cloud affected the overpressure range. However, the overpressures of pancake-shaped cloud decreased when the $\varepsilon$ increased from 5.7 to 5.8 and the decrement of overpressure was less than $12.50 \%$. Similarly, the increment of overpressure reaches $51.61 \%$ when the diameter-to-height ratio increased from 5.6 to 5.7 . Therefore, simply enlarging the diameters of the pancake-shaped cloud does not expand the range of overpressure. Only the appropriate $\varepsilon$ of pancake-shaped cloud can result in the largest range of overpressure. 
TABLE 2: Peak overpressure with $\varepsilon$ at the fixed distance.

\begin{tabular}{|c|c|c|c|c|c|}
\hline \multirow[b]{2}{*}{ Distance $/ \mathrm{m}$} & \multicolumn{3}{|c|}{$\varepsilon^{*}$} & \multicolumn{2}{|c|}{ Rate } \\
\hline & 5.6 & 5.7 & 5.8 & $\begin{array}{c}\text { Increase } \% \\
\Delta \varepsilon=\varepsilon_{2}-\varepsilon_{1}=0.1\end{array}$ & $\begin{array}{c}\text { Decrease } \% \\
\Delta \varepsilon=\varepsilon_{3}-\varepsilon_{2}=0.1\end{array}$ \\
\hline $5-10$ & 0.716 & 0.943 & 0.815 & - & - \\
\hline 15 & 0.126 & 0.132 & 0.125 & 4.76 & 5.30 \\
\hline 20 & 0.062 & 0.075 & 0.073 & 20.97 & 2.67 \\
\hline 30 & 0.031 & 0.047 & 0.046 & 51.61 & 2.13 \\
\hline 40 & 0.025 & 0.032 & 0.028 & 28.00 & 12.50 \\
\hline 50 & 0.019 & 0.024 & 0.021 & 26.32 & 12.50 \\
\hline
\end{tabular}

$\varepsilon^{*}$ represents diameters-to-height ratios.

TABLE 3: Comparative experimental and theoretical overpressure of cloud detonation for different sizes cloud.

\begin{tabular}{lccccccc}
\hline \multicolumn{7}{c}{} & \multicolumn{5}{c}{$\begin{array}{c}\text { Experimental overpressure/MPa } \\
\text { Distance/m }\end{array}$} & \multicolumn{7}{c}{$\begin{array}{c}\text { Cloud shape } \\
\text { TNO MEM overpressure/MPa }\end{array}$} \\
\hline$R=15$ & 0.126 & 0.195 & 0.221 & 0.126 & 0.12 & 0.124 & 0.31 \\
$R=20$ & 0.062 & 0.096 & 0.117 & 0.062 & 0.064 & 0.066 & 0.068 \\
$R=30$ & 0.031 & 0.046 & 0.056 & 0.034 & 0.038 & 0.039 & 0.042 \\
$R=40$ & 0.024 & 0.031 & 0.036 & 0.025 & 0.026 & 0.028 & 0.031 \\
$R=50$ & 0.019 & 0.021 & 0.024 & 0.019 & 0.019 & 0.021 & 0.020 \\
\hline
\end{tabular}

3.5. Theoretical Estimation of Overpressure by TNO MEM. The Netherlands Organization Multi-Energy Model (TNO MEM) [17] is a simple method for vapor cloud explosion blast modeling based on the multienergy concept. The results can be expressed with the distance to center of the cloud and the explosion strength. The 10-level strength of the explosion was recommended as the overpressure to be expected from a detonation.

The TNO MEM implies that

$$
\begin{aligned}
& \bar{R}=R\left(\frac{P_{0}}{E}\right)^{1 / 3}, \\
& \bar{P}_{s}=\frac{P_{s}}{P_{0}},
\end{aligned}
$$

where $\bar{P}_{s}$ is dimensionless maximum overpressure; $\bar{R}$ is combustion energy-scaled distance; $E$ is total energy for explosion source, MJ; $P_{0}$ is atmospheric pressure; $\mathrm{Pa}$ and $P_{0}$ are given as standard atmospheric pressure, $1.01 \times 10^{5} \mathrm{~Pa} ; R$ is the distance to center of the cloud, $\mathrm{m}$.

Assuming that the behaviors of the fuel mixture are similar to those of diethyl ether, the peak overpressure within a certain distance can be estimated by TNO MEM method. The changes of overpressure with distance were computed according to (3) (Table 3). These values were compared with the results of overpressure experiments. TNO MEM was established without considering the initial shape of cloud. In the center ignition and flame propagation for constant speed with hemispherical gas cloud model, a group of strengths of the explosion was calculated by the numerical method. Thus, the estimated values were related to the total energy of explosion source. The results in Table 3 indicate that experimental and TNO values show the similar change tendency of overpressure with distance. In shock wave zone, the values of overpressure are consistent with the TNO estimated values. However, the values of overpressure near detonation wave zone are lower than that of TNO. These minor differences in the values of overpressure are ascribed to the simple assumption of TNT MEM, measurement errors in experiments, and the properties of fuel.

\section{Conclusions}

In the paper, we studied the influence of the shape of cloud on detonation parameters. The main conclusions can be summarized as follows:

(1) According to the changing trend of the overpressure of fuel-air cloud, the range of overpressure was divided into the detonation wave zone and the shock wave zone. In the detonation wave zone, the maximum overpressure was acquired and the peak overpressures decreased significantly in the shock wave zone. The decrement of peak overpressure was between $82.40 \%$ and $20.83 \%$.

(2) The overpressure of cylindrical fuel-air cloud at the same distance increases with the increase in the diameter. However, the height of cloud shows little impact on the overpressure in the shock wave zone. Therefore, increasing the diameter of cylindrical cloud can increase the overpressure range under the same conditions. Based on the influences of the diameter and height of cylindrical cloud on the overpressure, 
the explosion of pancake-shaped cloud of fuel-air mixtures realizes the larger overpressure range.

(3) Though the pancake-shaped cloud produces the larger range of overpressure, the influencing range of the overpressure is affected by diameter-to-height ratio $\varepsilon$. Thus, the optimal diameter-to-height ratio of 5.7 allows the maximum peak overpressure for the same distance within the studied range.

The study results can be applied in the industry and military. In the military, the tendency for fuel-air clouds to form pancake shapes could significantly enhance the influencing range of the overpressure effect. In the industry, the factors of cloud shape should be included in hazard assessments and hazard analysis when the large quantities of fuel were handled during the storage, processing, sale, and transport.

\section{Competing Interests}

The authors declare that they have no competing interests.

\section{References}

[1] Y. Wang and F. Ma, The Theory of New Conception Weapon, Engineering and Industry Publications, Beijing, China, 1997.

[2] X.-Q. Yan and J.-L. Yu, "Overpressure characteristics of aluminium dust explosion vented through a relief pipe," Journal of Loss Prevention in the Process Industries, vol. 26, no. 4, pp. 676682, 2013.

[3] A. Klippel, M. Scheid, J. Koperski, M. Wappler, and U. Krause, "Influence of dustiness on small-scale vented dust explosions," Journal of Loss Prevention in the Process Industries, vol. 26, no. 6, pp. 1433-1441, 2013.

[4] J. C. Leyer, "An experimental study of pressure fields by exploding cylindrical clouds," Combustion and Flame, vol. 48, pp. 251-263, 1982.

[5] C. Bai, B. Fan, and B. Li, "Improvement of a gas intake device and a gas mixing study in a large-scale vessel," Chemical Engineering and Technology, vol. 37, no. 10, pp. 1751-1756, 2014.

[6] A. Miyake, H. Kobayashi, H. Echigoya et al., "Detonation characteristics of ammonium nitrate and activated carbon mixtures," Journal of Loss Prevention in the Process Industries, vol. 20, no. 4-6, pp. 584-588, 2007.

[7] Y. K. Pu, F. Jia, S. F. Wang, and T. Skjold, "Determination of the maximum effective burning velocity of dust-air mixtures in constant volume combustion," Journal of Loss Prevention in the Process Industries, vol. 20, no. 4-6, pp. 462-469, 2007.

[8] V. V. Koren'kov and A. S. Obukhov, "Effect of the location of the detonation initiation point and the position of the air-fuel cloud on explosion-field parameters," Combustion, Explosion and Shock Waves, vol. 37, no. 6, pp. 688-697, 2001.

[9] J. K. Clutter and J. Mathis, "Computational modeling of vapor cloud explosions in off-shore rigs using a flame-speed based combustion model," Journal of Loss Prevention in the Process Industries, vol. 15, no. 5, pp. 391-401, 2002.

[10] Q. Zhang, W. Li, D.-C. Lin, N. He, and Y. Duan, "Influence of nitromethane concentration on ignition energy and explosion parameters in gaseous nitromethane/air mixtures," Journal of Hazardous Materials, vol. 185, no. 2-3, pp. 756-762, 2011.
[11] L. Qingming and B. Chunhua, "Research on the explosion temperature response of fuel air explosive measured by colorimetric pyrometer," Journal of China Ordnance, vol. 6, no. 1, pp. 59-64, 2010.

[12] D. A. Yagodnikov, "Experimental study of combustion of a cloud of boron particles in air," Combustion, Explosion and Shock Waves, vol. 46, no. 4, pp. 426-432, 2010.

[13] G. Liu, F. Hou, B. Cao, and L. Xie, "Experimental study of fuelair explosive," Combustion, Explosion, and Shock Waves, vol. 44, no. 1, pp. 101-105, 2008.

[14] A. A. Borisov, B. E. Gel'Fand, S. A. Gubin, S. I. Sumskoi, and A. V. A. Shargatov, "Detonation of fuel-air mixtures above the surface of the earth," Combustion, Explosion, and Shock Waves, vol. 24, no. 2, pp. 238-240, 1988.

[15] B. Fishburn, N. Slagg, and P. Lu, "Blast effect from a pancake shaped fuel drop-air cloud detonation (theory and experiment)," Journal of Hazardous Materials, vol. 5, no. 1-2, pp. 65-75, 1981.

[16] L. Jiang, C.-H. Bai, and Q.-M. Liu, "Experimental study on DDT process in 3-phase suspensions of gas/solid particle/liquid mist mixture," Explosion and Shock Waves, vol. 30, no. 6, pp. 588-592, 2010.

[17] A. Apparao, C. R. Rao, and S. P. Tewari, "Studies on formation of unconfined detonable vapor cloud using explosive means," Journal of Hazardous Materials, vol. 254-255, no. 1, pp. 214-220, 2013. 


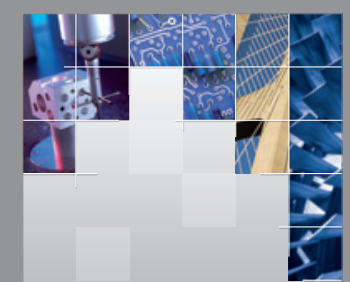

\section{Enfincering}
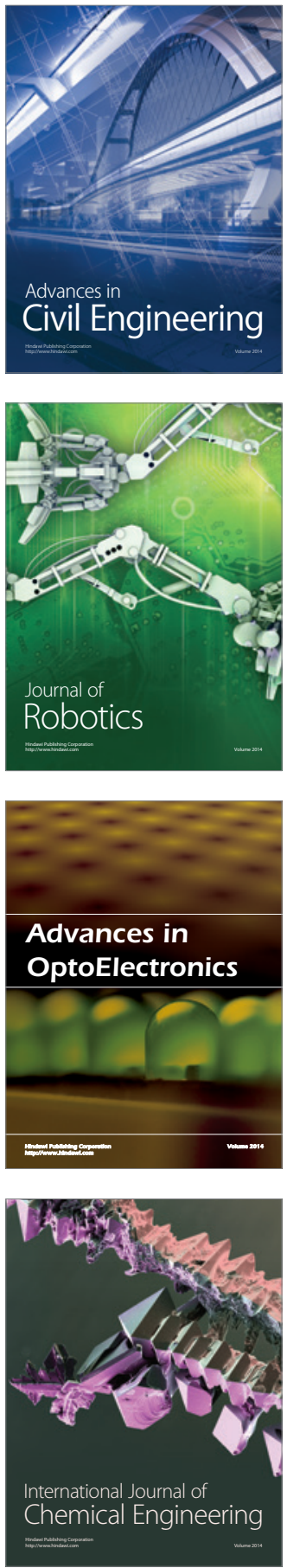

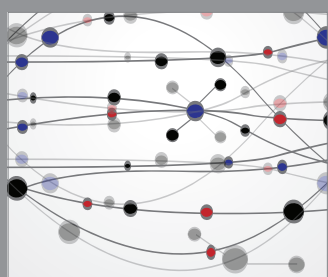

The Scientific World Journal

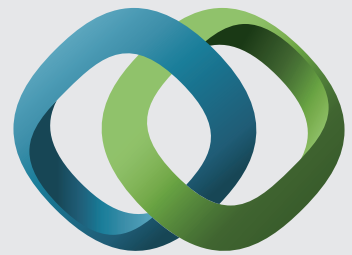

\section{Hindawi}

Submit your manuscripts at

http://www.hindawi.com
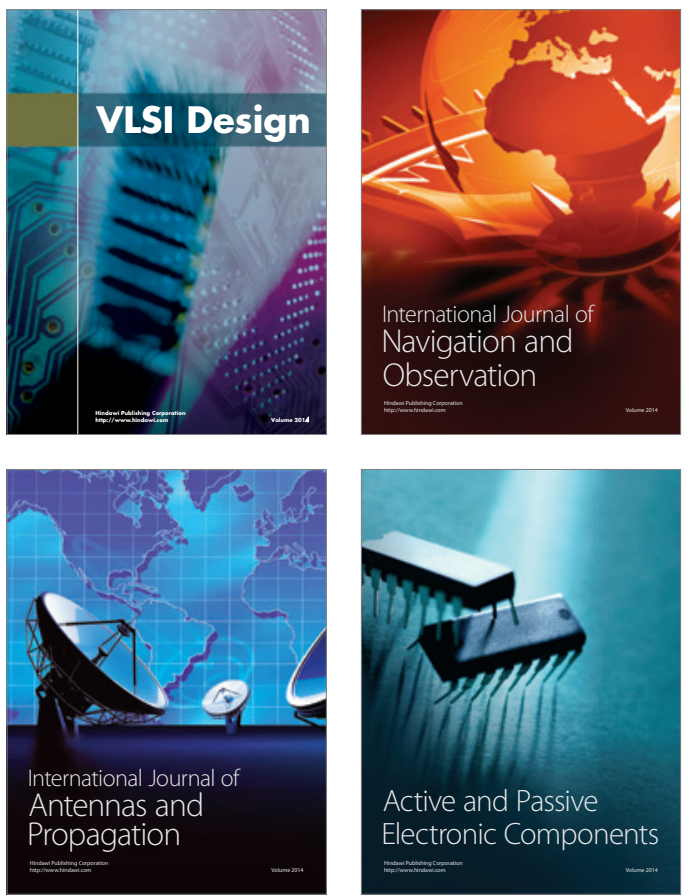
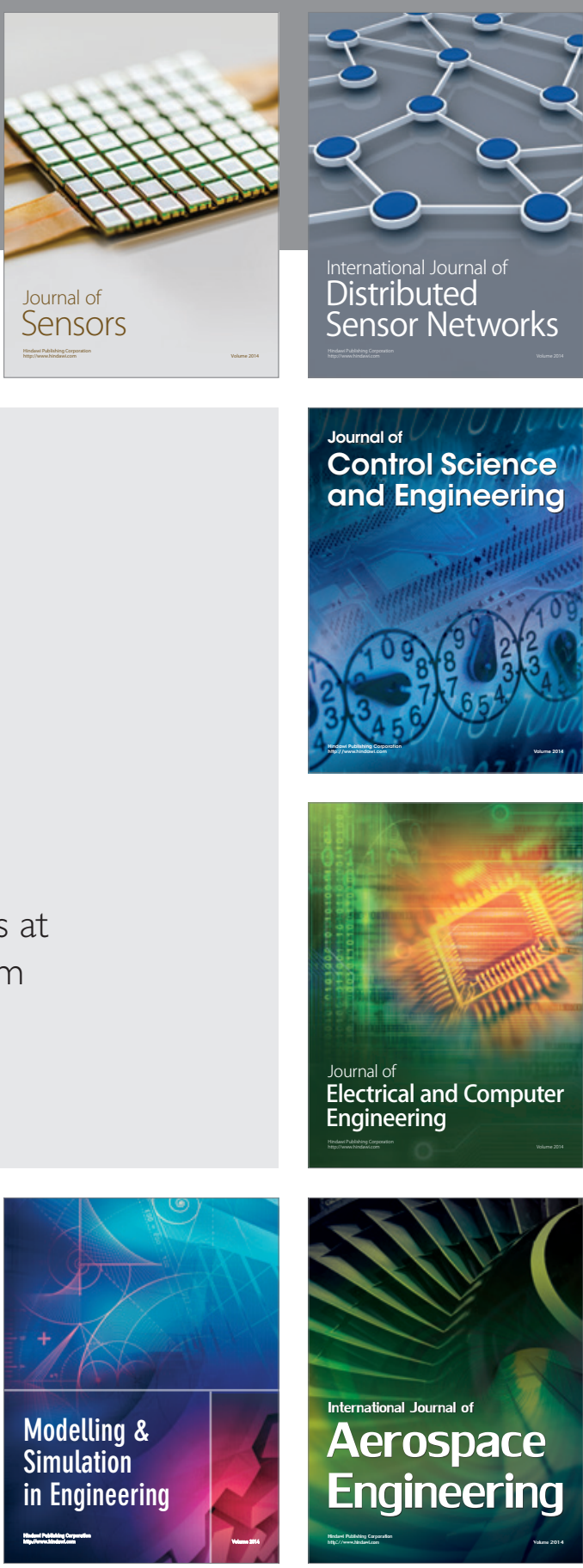

International Journal of

Distributed

Sensor Networks

Journal of

Control Science

and Engineering
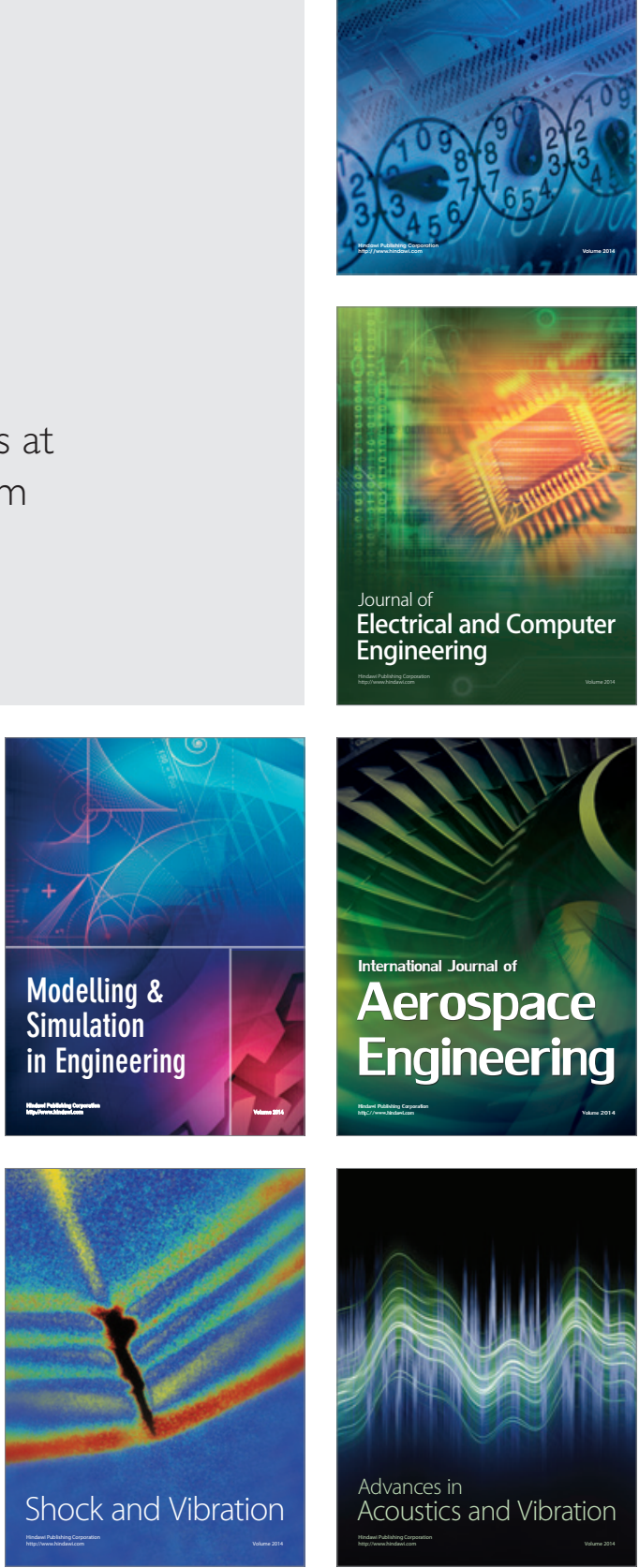